\title{
Editorial
}

\section{Advanced Nanostructured Semiconductor Materials: Morphology Controlled Synthesis and Application}

\author{
Gengxin Zhang,, Xin Zhang, ${ }^{2}$ Javad Foroughi, ${ }^{3}$ \\ Jimin Yao, ${ }^{1}$ and Jia Liu ${ }^{2}$ \\ ${ }^{1}$ Intel Corporation, Santa Clara, CA, USA \\ ${ }^{2}$ Pacific Northwest National Laboratory, Richland, WA, USA \\ ${ }^{3}$ University of Wollongong, Wollongong, NSW, Australia \\ Correspondence should be addressed to Gengxin Zhang; gengxin.zhang@intel.com
}

Received 26 February 2017; Accepted 27 February 2017; Published 8 March 2017

Copyright (c) 2017 Gengxin Zhang et al. This is an open access article distributed under the Creative Commons Attribution License, which permits unrestricted use, distribution, and reproduction in any medium, provided the original work is properly cited.

The increasing interest in morphology-control synthesized semiconductor nanomaterials and promising properties have led to the expanded application of semiconductor nanomaterials in nanoelectronics, field-effect transistor, lightemitting diodes, lasers, solar cells, chemical sensors and biosensors, nanopackaging, and catalysts. To date, various techniques such as chemical synthesis, self-assembly, and nanomanufacturing of bulk or layered wafers have been applied to morphology controlled synthesis novel semiconductor nanomaterials. We encourage the submissions of new methods and techniques in the morphology controlled synthesis and/or fabricated semiconductor nanomaterials and understanding the advanced optical, mechanical, electrical, or thermal properties of these as-prepared semiconductor nanomaterials. In this special issue, we invited researchers to contribute original articles as well as reviews that address the field of advanced nanostructured semiconductor materials. Today, we are very glad to see the sunset of issue with 5 research articles and one review paper published.

\section{Acknowledgments}

We would like to warmly give thanks to all authors who submitted their works to this issue, the colleagues who act as reviewers of one or more manuscripts, as their professionalism and support for both authors and theEditorial Board are much appreciated, and the editors who have spent their time in reviewers selection and the final decision.

Gengxin Zhang

Xin Zhang

Javad Foroughi

Jimin Yao

Jia Liu 

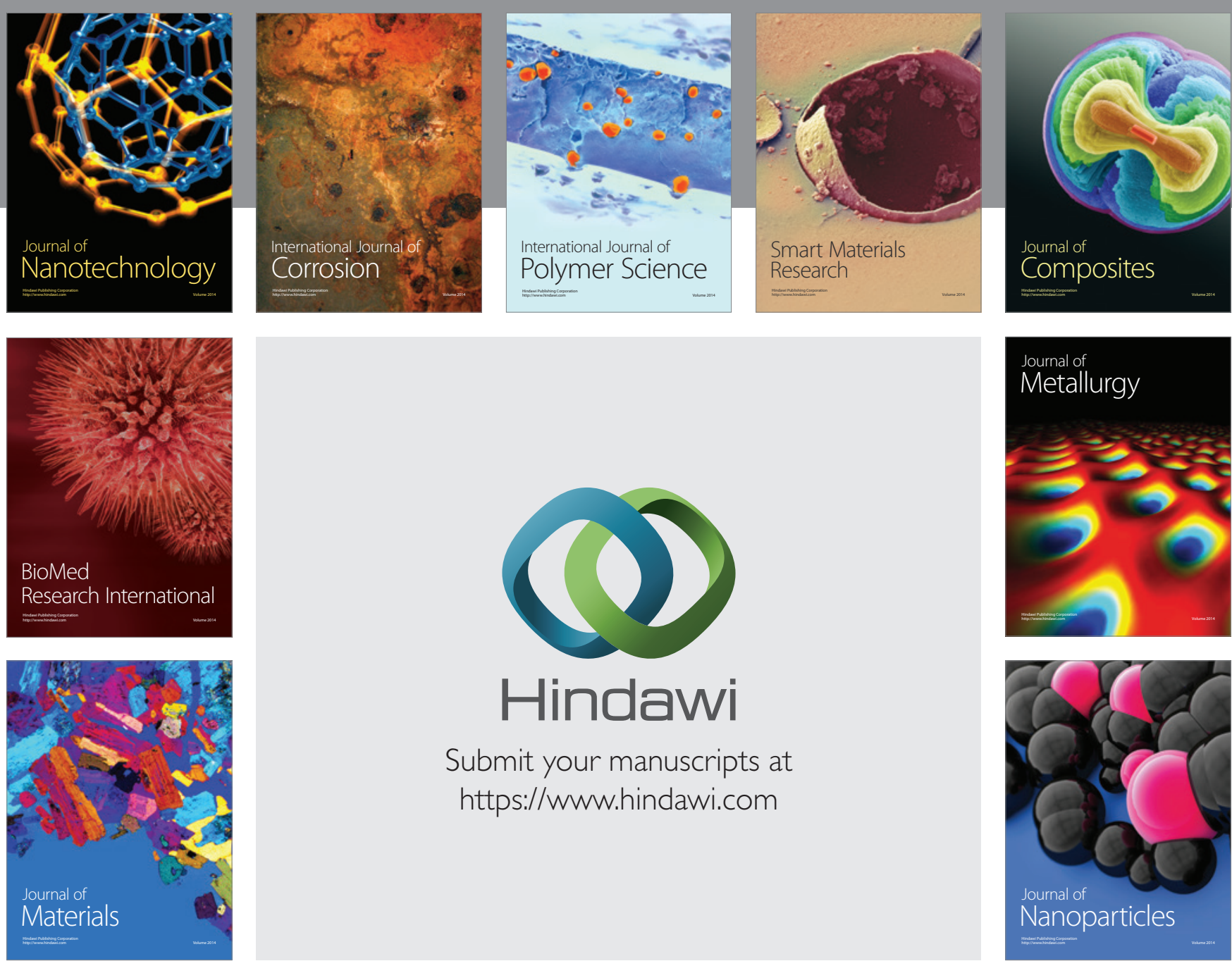

\section{Hindawi}

Submit your manuscripts at

https://www.hindawi.com

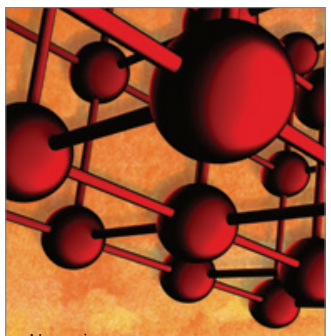

Materials Science and Engineering
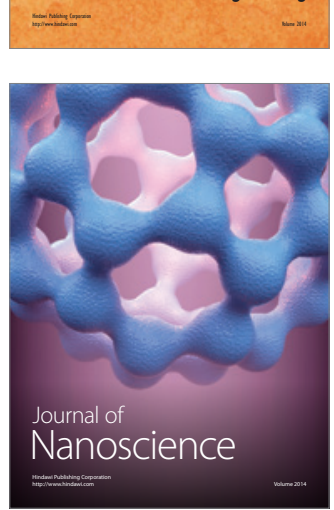
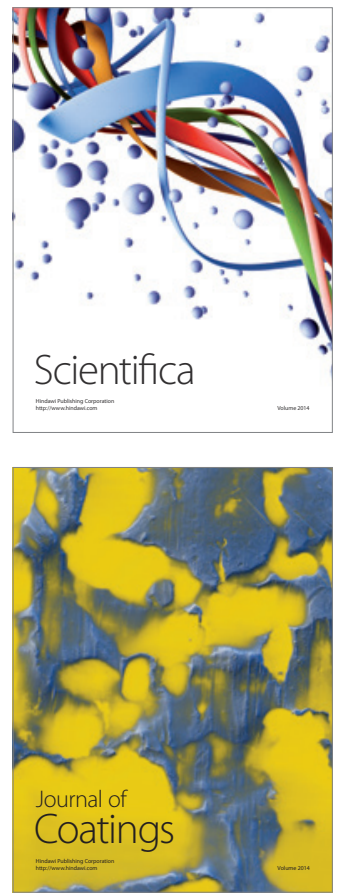
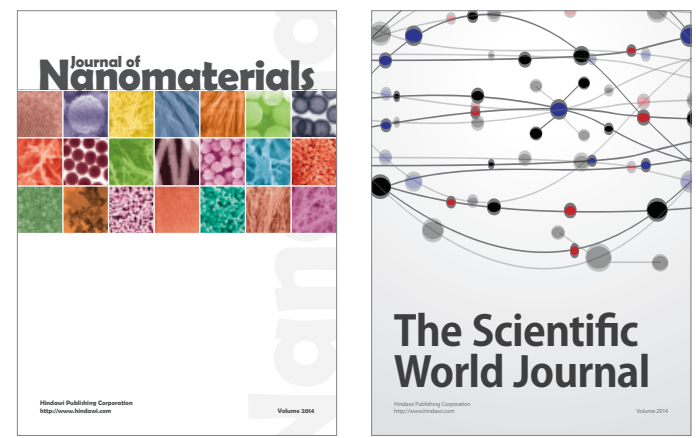

The Scientific World Journal
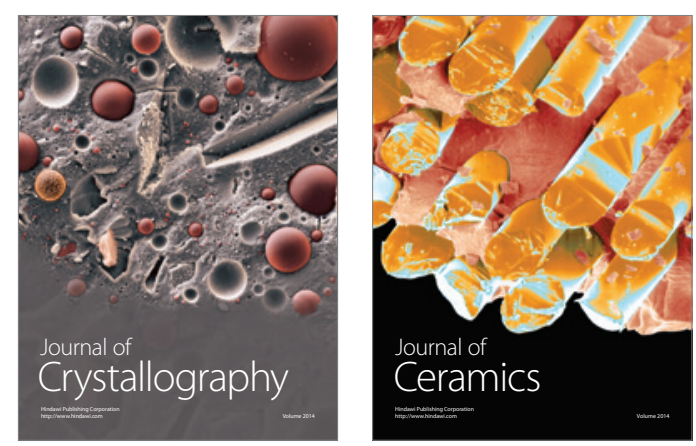
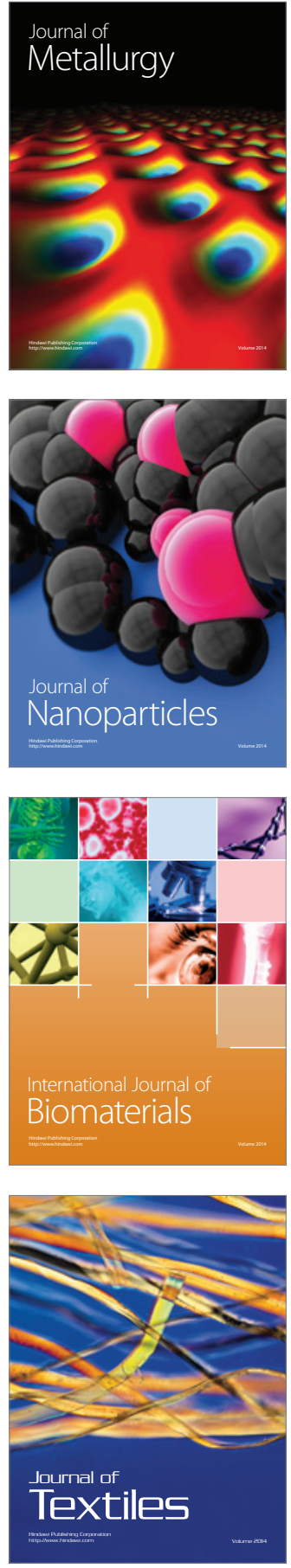